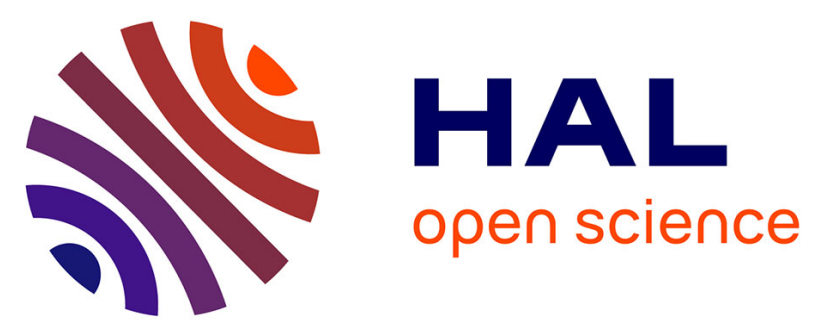

\title{
Halving food-related greenhouse gas emissions can be achieved by redistributing meat consumption: progressive optimization Results of the NutriNet-Santé cohort
}

\author{
Emmanuelle Kesse-Guyot, Hélène Fouillet, Julia Baudry, Alison Dussot, \\ Brigitte Langevin, Benjamin Allès, Pauline Rebouillat, Joséphine Brunin, \\ Mathilde Touvier, Serge Hercberg, et al.
}

\section{- To cite this version:}

Emmanuelle Kesse-Guyot, Hélène Fouillet, Julia Baudry, Alison Dussot, Brigitte Langevin, et al.. Halving food-related greenhouse gas emissions can be achieved by redistributing meat consumption: progressive optimization Results of the NutriNet-Santé cohort. Science of the Total Environment, 2021, 789, pp.147901. 10.1016/j.scitotenv.2021.147901 . hal-03238402

\author{
HAL Id: hal-03238402 \\ https://hal.inrae.fr/hal-03238402
}

Submitted on 27 May 2021

HAL is a multi-disciplinary open access archive for the deposit and dissemination of scientific research documents, whether they are published or not. The documents may come from teaching and research institutions in France or abroad, or from public or private research centers.
L'archive ouverte pluridisciplinaire HAL, est destinée au dépôt et à la diffusion de documents scientifiques de niveau recherche, publiés ou non, émanant des établissements d'enseignement et de recherche français ou étrangers, des laboratoires publics ou privés. 
Halving food-related greenhouse gas emissions can be achieved by redistributing meat consumption: progressive optimization Results of the NutriNet-Santé cohort

Emmanuelle Kesse-Guyot ${ }^{1}$, Hélène Fouillet ${ }^{2}$, Julia Baudry ${ }^{1}$, Alison Dussot ${ }^{2}$, Brigitte Langevin ${ }^{5}$, Benjamin Allès ${ }^{1}$, Pauline Rebouillat ${ }^{1}$, Joséphine Brunin ${ }^{1,6}$, Mathilde Touvier ${ }^{1}$, Serge Hercberg ${ }^{1,3}$, Denis Lairon $^{4}$, François Mariotti ${ }^{2}$, Philippe Pointereau ${ }^{5}$

${ }^{1}$ Sorbonne Paris Nord University, Inserm, INRAE, Cnam, Nutritional Epidemiology Research Team (EREN), Epidemiology and Statistics Research Center - University of Paris (CRESS), 93017

Bobigny, France

${ }^{2}$ UMR PNCA, AgroParisTech, INRAE, Université Paris-Saclay, 75005, Paris, France

${ }^{3}$ Département de Santé Publique, Hôpital Avicenne, 93017 Bobigny, France

${ }^{4}$ Aix Marseille Université, INSERM, INRAE, C2VN, 13005 Marseille, France

${ }^{5}$ Solagro, 75, Voie TOEC, CS 27608, F-31076 Toulouse Cedex 3, France

${ }^{6}$ ADEME, Agence de l'Environnement et de la Maîtrise de l'Energie), 49004 Angers, France

Correspondence: Email: e.kesse@eren.smbh.univ-paris13.fr

Equipe de Recherche en Epidémiologie Nutritionnelle (EREN)

SMBH Université Sorbonne Paris Nord, 74 rue Marcel Cachin, 93017 Bobigny, France

Running title: Low-Greenhouse Gas Emissions optimized diets

Keywords: diet sustainability, greenhouse gas emissions, optimization modelling, co-product tradeoffs

Number of tables: 3/Number of figures: 3

Appendix: 4 tables and 3 figures 


\section{$1 \quad$ Abstract 300 words}

2 Background: Diet-related greenhouse gas emissions (GHGe) mainly comes from animal-sourced

3 foods. As progressive changes are more acceptable for a sustainable food transition, we aimed to

4 identify nutritionally adequate and culturally acceptable optimized diets ensuring a gradual reduction

5 in GHGe, using observed diet from a large sample of French adults, while considering the mode of

6 food production (organic vs conventional farming) and the co-production link between milk and beef.

7 Material and method: Based on the consumption of 257 organic and conventional foods among

829,413 participants (75\% women, age: $53.5 \pm 14.0 \mathrm{y}$ ) of the NutriNet-Santé study, we modelled optimal

9 diets according to GHGe reduction scenarios in 5\% steps, from 0 to $50 \%$ with nutritional, acceptability, and coproduct constraints, for men, premenopausal and menopausal women separately.

11 Results: Gradual GHGe decrease under these constraints led to optimal diets with an overall decrease 12 in animal foods, with marked reductions in dairy products (up to -83\%), together with a stable but 13 largely redistributed meat consumption in favor of poultry (up to $+182 \%$ ) and pork (up to $+46 \%$ ) and 14 at the expense of ruminant meat (down to $-92 \%$ ). Amounts of legumes increases dramatically (up to $15+238 \%$ ). The greater the reduction in diet-related GHGe, the lower the cumulative energy demand (about $-25 \%$ ) and land use (about $-43 \%$ ). The proportion of organic food increased from $~ 30 \%$ in the observed diets to $\sim 70 \%$ in the optimized diets.

18 Conclusion: Our results suggest that meeting both nutrient reference value and environmental 19 objectives of up to 50\% GHGe reduction requires the reduction of animal foods together with 20 important substitutions between animal food groups, which result in drastic reductions in beef and 21 dairy products. Further research is required to explore alignment with long-term health value and conflict with acceptability, in particular for even greater GHGe reductions. 


\section{Introduction}

The current environmental crisis, beyond the irreversible damage to natural resources, is characterized by climate change and global warming (defined as the increase of both air and sea surface temperature over a long period of time (>30 years)). Thus, anthropogenic global warming in 2017 was $+1{ }^{\circ} \mathrm{C}$ compared to pre-industrial levels (1850-1900), i.e. about $0.2^{\circ} \mathrm{C}$ per decade (1).

Food systems are responsible for about $30 \%$ of global greenhouse gas emissions (GHGe) (2) and are major users of fresh water, therefore largely contributing to climate change (3). Unless action is taken in the next decades, various prospective scenarios have estimated that, by 2050 , unsustainable diets will lead to an additional $80 \%$ rise in GHGe compared to the current situation (4). To mitigate climate change below $1.5^{\circ} \mathrm{C}$, some scenarios have documented that halving agricultural carbon footprint by 2050 would be necessary (5) and this would require strong dietary changes on a global scale (6).

The scientific literature about GHGe related to dietary patterns, based on optimization-based modelling and observational data, is growing and is consistently reporting that plant-based diets exhibit lower GHGe compared to those rich in animal products (7-10). Plant-based dietary patterns can also help to prevent chronic diseases $(3,11-14)$, underlying co-benefits of plant-based diets for climate mitigation and human health promotion. Clark et al. (14) have documented, based on metadata, that beneficial foods for health, apart from fish, generally exhibit lower environmental pressures, encompassing GHGe, acidification, eutrophication, land and water use. Conversely, some foods which could be detrimental for health, such as red meat and processed meat (associated with increased risk for various health outcomes, including mortality and morbidity due to coronary heart diseases, stroke, diabetes and colorectal cancer), are also the highest contributors to diet-related GHGe and large variations in GHGe exist across food groups (14).

However, the question of how to achieve changes in dietary behavior including a reduction in meat consumption and more generally animal-based food has not been resolved (15). Indeed, food choices are diverse and based on multiple influencing factors which may constitute barriers $(15,16)$. Thus, the strategies accompanying the transitions towards greater sustainability and in particular lower GHGe should be multiple and adapted to different types of consumers (17). We may hypothesize that among traditional high meat consumers, a first step of the transition can be based on intra-food group substitutions, especially due to cultural traits that hinder large reduction in meat consumption $(18,19)$. For instance, in France, a previous study modelled a gradual reduction in GHGe and showed that a $30 \%$ reduction was possible without drastically deviating from the current diets while respecting nutritional constraints and diet cost (20). Among the gaps in existing studies we can mention the following. First, most modelling studies used GHGe as constraints or objective function (10) but few have considered other environmental indicators in their analysis - as descriptors, constraints or objective - despite the fact that some conflicts are known to occur among the different environmental dimensions, which are related to the general organization of the food system, such as energy demand and land occupation (21). Besides, few studies have distinguished conventional and eco-friendly 
production systems, as the data are generally based on life cycle assessment (LCA) for generic foods. Although organic farming has not been systematically related to lower GHGe, energy demand is lower while land use is higher compared to conventional agriculture $(22,23)$. In a previous work based on observational data distinguishing between organic and conventional diets, we observed that diets with high GHGe were higher in animal-based food, more caloric and nutritionally less healthy (24). Thus, the role of various food systems on environmental pressure has not been yet considered enough (25). Finally, food systems also include some important structural determinants of food production, such as the fact that co-productions rules are often operating, as for milk and beef meat productions, but is rarely considered (26-28).

We can hypothesize that transitions to sustainable diets will require to activate all the levers and substitution is one of them. Thus, the objective of this study was to test whether the possibility to reduce GHGe of production by $50 \%$ as defined in the Paris agreement (29) in a set of culturally acceptable diets. We modelled dietary pattern characteristics with gradual decreasing GHGe under nutritional, coproduction and acceptability constraints and to relate these dietary patterns to other environmental indicators while considering two different food production systems, organic and conventional.

\section{Methods}

\subsection{Population}

The population included adults participating in the ongoing web-based prospective NutriNet-Santé cohort initiated in France in May 2009 (and on-going) whose aim is to investigate relationships between nutrition and health (30). Participants are recruited on a voluntary basis from the general French population. This study is conducted in accordance with the Declaration of Helsinki, and all procedures were approved by the Institutional Review Board of the French Institute for Health and Medical Research (IRB Inserm 0000388FWA00005831) and the National Commission on Informatics and Liberty (Commission Nationale de l'Informatique et des Libertés, CNIL 908450 and 909216). Electronic informed consent was obtained from all participants. The NutriNet-Santé study is registered in ClinicalTrials.gov (NCT03335644). At baseline and every year thereafter, participants provide data about their sociodemographic and economic status, anthropometrics, lifestyles and dietary intakes through self-administered questionnaires. They are also regularly invited to fill in complementary questionnaires.

\subsection{Sociodemographic and lifestyle characteristics}

Participants completed regularly validated questionnaires about sociodemographic and lifestyle features $(31,32)$, thus data from the sociodemographic questionnaires that were the closest to the dietary questionnaire were used. Sociodemographic and lifestyle characteristics encompassed gender, age, education (<high school diploma, high school diploma, and post-secondary graduate), smoking 
95 status (former, current, or never-smoker), and physical activity assessed using the International

96 Physical Activity questionnaire (33).

$97 \quad 2.3$ Dietary data assessment

98 The present study is based on dietary data collected through a self-administered validated semi-

99 quantitative food frequency questionnaire (FFQ), administered from June to December 2014. This

100 questionnaire has been enriched by a five-point ordinal scale for each of the 264 food and beverage

101 items to evaluate the share of organic food consumption (under official labels) (34). Organic

102 production is one of the official signs of quality and origin in France. This method is governed by a

103 European regulation since 1991, with the overall objectives of ensuring respect of the environment,

104 biodiversity and animal welfare (35) recently updated (EU regulations 2018/848 and 2020/464 coming

105 into force in January 2022. More specifically, for each item, participants were asked 'How often was

106 the product of organic origin?' with the following answer modalities: "never", "rarely", "half-of-

107 time", "often" or "always". This questionnaire developed within the frame of the BioNutriNet project

108 has been extensively described elsewhere (22). Organic food consumption was estimated by allocating

109 the respective weights: 0, 25, 50, 75 and 100 to the modalities. For clarity purpose, food and beverage

110 items were grouped into 16 food groups as presented in Appendix A. Nutrient intake were calculated

111 using a published food composition database (36). 


\subsection{Environmental pressure indicators}

Environmental indicators were assessed using the DIALECTE tool, established by Solagro (Toulouse, France) (37), whose aim is to evaluate environmental impacts of French farming systems using attributional life cycle analysis (LCA) without considering land use change. The perimeter of LCA was restricted to the agricultural production phase (conditioning, transport, processing, storage or recycling stages were not considered). Upstream processes were therefore included in the assessment, such as input production or energy supply. Three environmental indicators were considered at the farm level: the GHGe measured as $\mathrm{kg}$ of $\mathrm{CO}_{2}$ equivalents $\left(\mathrm{CO}_{2} \mathrm{eq}\right)$, the cumulative energy demand (CED) in $\mathrm{MJ}$, and the land occupation expressed in $\mathrm{m}^{2}$ for $>60$ raw products (24). The original database has been completed by other data sources that have been previously listed (24), to obtain environmental pressures in organic and conventional of 92 raw agricultural products covering the 264 food items. Data have been published elsewhere (24). Environmental pressures of the FFQ food items as consumed were retrieved from the 92 raw agricultural products by using a set of conversion coefficients (economic allocation (accounting for co-products) and cooking and edibility coefficients.

\section{Coproduct factors for ruminant products}

We considered a meat to carcass weight ratio of $68 \%$ (38), and further yields of $90 \%$ during distribution (due to $10 \%$ distribution losses) and 68\% during consumption (due to $32 \%$ losses by cooking, bones and wastes) (38).

In 2010 in France, 25 million tons of milk and 1.52 million tons of beef (expressed in carcass weight) (5) were produced, of which $41 \%$ was from dairy herd, i.e., 0.62 million tons of beed (39). Thus, 1L of milk corresponded to $10 \mathrm{~g}$ of beef when applying the equation (1):

(1) 25 million tons of Milk (L) $=1.52$ million tons of beef $\times 41 \% \times 68 \%{ }_{\text {carcass yield }} \times$

$$
90 \%_{\text {distribution yield }} \times 68 \%_{\text {preparation yield }}
$$

Furthermore, we considered that $8 \mathrm{~L}$ of milk are required to make $1 \mathrm{~kg}$ of cheese and $1 \mathrm{~L}$ of milk to make $1 \mathrm{~kg}$ of fresh dairy products, using the average figures from French processing chains. 2.6 Diets modelling and optimization As nutrient requirements vary according to population subgroups, participants were grouped as men, premenopausal women and menopausal women and diets were modeled for each subgroup to account for differences in iron intake requirements. Postmenopausal women were considered to have a low iron requirement and premenopausal women have a high iron requirement (the highest reference value, i.e. the reference covering $97.5 \%$ of the women requirements; of note most women (80\%) have much lower requirements). Data related to observed food consumption as well as attributes of food items, i.e. nutritional composition, environmental pressures and production mode (conventional or 
organic), were used to define optimized diets being nutritionally adequate, acceptable, and more sustainable.

Nutritional adequacy was ensured by a set of nutritional constraints by considering, in particular, nutrient bioavailability for iron and zinc, as described in Appendix B.

The list of constraints was as follows:

- Nutritional constraints on total energy and 31 nutrients, with upper and/or lower bounds based on nutrient reference intakes. Lower bounds were taken as recommended dietary allowance (population reference intake) or adequate intake, or lower bound of reference intake range for the French population (40) as mostly derived from the EFSA opinion (41). For some nutrients, when the adequate intake was based on the observed average intake, the lower bound was set as the value of the $5^{\text {th }}$ percentile. Reference intakes also included upper levels, as tolerable upper intakes for vitamins and minerals, when identified, and upper bound of reference intake range.

- Acceptability constraints on some food groups, with upper bounds set as the populationspecific $95^{\text {th }}$ percentiles for $37 \mathrm{ad}$-hoc food groups. Additional moderation constraints on some food groups (dairy products $\leq 2$ portions/d, fish $\leq 2$ portions/week with 1 of fatty fish, and red meat $<500 \mathrm{~g} /$ week), to comply with national public health moderation recommendations for animal products, as prescribed in French food-based dietary guidelines (42).

- Co-production constraint limiting the consumption of milk to a proportion of that of beef, using the factor between milk and beef defined above in Eq. (1).

- Environmental constraint for a given (from 0 to $-50 \%$ by $5 \%$ decrement) reduction in GHGe compared to the observed situation. For each food, during diet optimization, the model selected the production option (conventional or organic) exhibiting lower GHGe.

The objective corresponded to the maximization of acceptability, i.e. minimizing the total departure (D) from the observed diet (initial condition), as follows:

$$
\operatorname{Min} \mathrm{D}=\sum_{i}^{257}\left[\frac{O b s_{i}-O p t_{i}}{S D_{i}}\right]^{2}
$$

where $\mathrm{Obs}_{\mathrm{i}}$ and $\mathrm{Opt}_{\mathrm{i}}$ denote the daily consumption of food item (i) in the observed and optimized diets, respectively and $\mathrm{SD}_{\mathrm{i}}$ is the standard deviation of the observed daily consumption of food item (i).

The climatic improvement approach was examined using scenarios of 5\% gradual decreases in GHGe, by using a GHGe constraint in each scenario from $0 \%$ (basal model: GHGe $\leq$ Observed situation) to $50 \%$.

The optimization process was performed using the procedure SAS/OR $®$ optmodel (version 9.4; SAS Institute, Inc.) using the $n l p$ non-linear optimization algorithm (since the objective and some 
181 nutritional constraints were non-linear) and multistart option (to ensure that solutions were not only

182 local optimums).

183 During diet optimization, we estimated the standardized dual values (i.e., the dual values associated

184 with each constraint that has been standardized by its limiting bound), which represent the potential

185 gain in objective for a $100 \%$ relaxation of each constraint's limiting bound. This allowed to identify

186 the active ( $v s$. inactive) constraints and compare their relative influences on the results. To conduct

187 this sensitivity analysis even further, some alternative models were also tested, with either introducing

188 some flexibility in some constraints (like the bioavailable zinc and iron nutritional constraints) or the

189 suppression of some other (like the co-production constraint).

190 Consumptions of food groups, animal- and plant-based products, nutrient intakes, percentage of

191 organic production mode per food group, monetary cots, environmental pressures (GHGe, cumulative

192 energy demand and land occupation) and the pReCiPe, as previously described (22), were calculated

193 for each optimized diet.

194 The pReCiPe (partial ReCiPe), a synthetic estimate of environmental impact based on GHGe,

195 cumulative energy demand and land occupation, which enables to consider potential trade-offs

196 between indicators (43), was calculated as follows:

197

$p R e C i P e=0.0459 \times G H G e+0.0025 \times C E D+0.0439 \times L O$

198

199 with $\mathrm{GHGe}$, in $\mathrm{kg}$ of $\mathrm{CO}_{2} \mathrm{eq} / \mathrm{d}, \mathrm{CED}$, in $\mathrm{MJ} / \mathrm{d}$ and $\mathrm{LO}$, in $\mathrm{m}^{2} / \mathrm{d}$. The higher the $\mathrm{pReCiPe}$, the higher the 200 environmental impact.

$201 \quad 2.7$ Statistical analysis

202 For the present study, we considered participants of the NutriNet-Santé study who had completed the

203 Org-FFQ between June and December 2014 ( $N=37,685)$, with no missing covariates $(\mathrm{N}=37,305)$, not

204 detected as under- or over-energy reporter $(\mathrm{N}=35,196)$, living in mainland France $(\mathrm{N}=34,453)$, and

205 with available data regarding the place of purchase for the computation of the dietary monetary cost,

206 leading to a final sample of 29,413 participants. The sociodemographic, lifestyle and dietary

207 characteristics were presented by subgroup (men, premenopausal and menopausal women).

208 Dietary consumptions per subgroup were presented as observed mean (SD) or optimized values for

209 scenarios for the main 16 food groups and further specifically detailed among both animal and plant-

210 based foods.

211 All statistical analyses were performed using SAS (version 9.4; SAS Institute, Inc., Cary, NC, USA).

\section{3. Results}

213 3.1 Sample characteristics.

214 The sociodemographic characteristics of the sample are presented in Table 1. The sample included in

215 the present analysis was constituted of 7,416 men, 9,710 premenopausal women and 12,287 
menopausal women. The mean age was 53.5y ( $\mathrm{SD}=14.0)$. Most of the sample was postgraduate (64\%) and few individuals were current smokers (11\%) or exhibited a low physical activity level (19\%). For each population (men, premenopausal and menopausal women), the food group consumptions for the observed diet and the optimized diet under each model and by each scenario of GHGe reduction are presented in Appendix $\mathbf{C}$.

\subsection{Overall dietary changes}

The overall food group composition of optimized diets meeting the set of nutritional, acceptability, moderation and coproduct constraints without (basal scenario, $0 \%$ reduction in GHGe) or with gradual GHGe reduction (following scenarios, up to $50 \%$ of the observed pressures), are presented in Figure 1. In the basal scenario ( $0 \%$ reduction in GHGe, where the optimized diet was the closest diet to the observed diet that meet the nutritional, acceptability, moderation and coproduct constraints), nutrient constraints resulted in decreases in butter (up to $-80 \%$ vs observed diet), dairy products (up to $-64 \%$ ), extra-foods (up to -75\%), non-alcoholic beverages (up to -54\%) and fish (up to -45\%) and in contrast increases in soya-based food (up to $+390 \%$ ), eggs (up to $+140 \%$ ) and mixed dishes (up to $+156 \%$ ), with also some sex-specific effects (whole starchy foods $45 \%$ decrease in men but $70 \%$ increase in women, starchy foods and vegetable oils $54 \%$ and $145 \%$ respectively increase in men). In the following scenarios, as detailed in the Appendix D , fulfilment of the environmental constraints of gradual up to $50 \%$ decrease in GHGe was ensured by gradual further increases in soya-based food in women (up to $+68 \%$ vs basal scenario) and eggs in all groups (up to $+24 \%$ ) and by gradual further decreases in extra-foods in all groups (up to -68\%), whole grains \& starchy foods, mixed dishes and dairy products in men $(-95 \%,-32 \%$ and $-32 \%$ respectively), in meat and vegetables oils in women (up to $-27 \%$ and $-29 \%$, respectively).

\subsection{Animal-based foods consumption}

Figure 2 presents the detailed intakes of animal-based foods in observed diets and in the optimized diets for the basal ( $0 \%$ reduction in GHGe) and following (up to $50 \%$ gradual decrease in GHGe) scenarios. Compared to the observed diets, in the basal scenario meeting the nutritional requirements, all optimized diets (whatever the population) were characterized by a reduction in total animal products (up to $-44 \%$ ), with suppression of milk and reductions in dairy products and cheese (up to $66 \%$ and $-30 \%$, respectively) and fish (up to $-45 \%$, to be reduced to its maximal recommendation), and in contrast increases in eggs and poultry (up to $+140 \%$ and $+182 \%$, respectively). Moreover, in the basal scenario compared to the observed situation, so as to ensure the nutrient requirements and animal-based food dietary guidelines, ruminant meat increased (up to $+30 \%$ in postmenopausal women) while pork meat decreased (up to $-89 \%$ in men). These trends for ruminant and pork meats were then reversed during the following scenarios of up to $50 \%$ reduction in GHGe, which were systematically characterized by concomitant and gradual decrease in ruminant meat (up to $-91 \%$ compared to the basal model with no GHGe decrease) and increase in pork (up to $+964 \%$ ). The GHGe $50 \%$ reduction was also ensured, to a lesser extent, by some sex-specific effects in line with those 
already observed in the basal scenario, namely a further dairy products reduction in men and a further egg increase in women.

Finally, compared to the observed diets, ensuring both nutritional needs, acceptability, moderation and coproduction constraints and 50\% GHGe reduction was achieved by strong reductions in the consumptions of fish and ruminant meat (up to $-23 \mathrm{~g} / \mathrm{d}$ and $-52 \mathrm{~g} / \mathrm{d}$ ) together with strong reductions in the consumptions of milk and dairy products (up to $-65 \mathrm{~g} / \mathrm{d}$ and $-115 \mathrm{~g} / \mathrm{d}$ ), while the consumptions of poultry, eggs and pork increased (up to $+46 \mathrm{~g} / \mathrm{d},+18 \mathrm{~g} / \mathrm{d}$ and $+18 \mathrm{~g} / \mathrm{d}$ ). Overall, if the total meat consumption remained relatively similar between the observed and optimized diets, it was strongly redistributed between meat types, as the contribution of poultry to total meat consumption greatly increased from $18 \%-24 \%$ in observed diets to $43 \%-50 \%$ in optimized diets, while the contribution of pork more moderately increased from $39 \%-42 \%$ to $46 \%-54 \%$ and the contribution of ruminant meat greatly decreased from $34 \%-41 \%$ to $3 \%-5 \%$.

\subsection{Plant-based foods consumption}

Figure 3 presents the detailed intakes of plant-based foods in the observed and optimized diets for the basal (0\% reduction in $\mathrm{GHGe}$ ) and following (up to $50 \%$ gradual decrease in $\mathrm{GHGe)} \mathrm{scenarios.}$ Compared to the observed diets, in the basal scenario meeting the nutritional requirements, all optimized diets were characterized by strong increases in legumes (up to $+238 \%$, i.e., $+45 \mathrm{~g} / \mathrm{d}$ ) and decreases in soups, soya-based food and fruits in all groups (up to $-97 \%,-81 \%$ and $-34 \%$, i.e., $-73 \mathrm{~g} / \mathrm{d}$ and $-3.6 \mathrm{~g} / \mathrm{d}$ and $-91 \mathrm{~g} / \mathrm{d}$ respectively). Whole grains and starchy foods decreased in men (-63\%, i.e. $59 \mathrm{~g} / \mathrm{d}$ ) but increase in women (up to $+52 \%$, i.e. $34 \mathrm{~g} / \mathrm{d}$ ). These effects were similar or even slightly further strengthened in the following scenarios of up to $50 \%$ GHGe reduction. Indeed, whole grains and starchy foods decreased in premenopausal women, increased in menopausal women and were almost totally suppressed in men. The $50 \%$ GHGe reduction was also achieved by a reduction in potatoes (up to $-69 \%$, i.e., $-21 \mathrm{~g} / \mathrm{d}$ ).

\subsection{Environmental and cost characteristics}

The evolution of environmental and monetary cost indicators across the different scenarios is presented in Table 2. Compared to the observed situation, the basal scenario meeting the nutrient reference values (without GHGe reduction) yielded an increase in almost all these indicators (energy demand and land occupation, pReCiPe and monetary cost of the diet). In the following scenarios of gradual GHGe reduction, all these indicators then gradually decreased and reached lower values than those observed for the environmental indicators, but not for the diet monetary cost. Indeed, compared to the observed situation, in the last scenario of 50\% GHGe reduction, the energy demand was lowered by up to $-29 \%$, land occupation by $-48 \%$ and pReCiPe by $-47 \%$, while the monetary cost of the diet increased between $+9 \%$ and $+20 \%$.

The share of organic food, starting from $26-32 \%$ in the observed diets, increased greatly and rapidly from the basal scenario and then stabilized around $65-70 \%$ in all optimized diets. As detailed in the 
289 Appendix E, while animal foods were consumed mostly as non-organic, plant-based food were

290 consumed as organic in optimized diet.

\subsection{Nutrient characteristics}

292 The nutrient intakes according to the observed and optimized diets are presented in Table 3 Notably,

293 in all optimized diets, the intakes of fibers and bioavailable zinc, which were insufficient in the

294 observed diets, were leveled up to their reference value and were then kept unchanged. We found

295 similar results for the intakes of bioavailable iron and vitamin B12, except that while they also

296 increased in all the optimized compared to observed diets, they nevertheless decreased among

297 optimized diets along with GHGe reductions. The intake of phytates was also gradually decreased as

298 GHGe was reduced, allowing meeting reference values for bioavailable iron and zinc. Calcium intake

299 increased in all optimized diets, except in menopausal women.

$300 \quad 3.7$ Active constraints and sensitivity analysis

301 Analysis of the standardized dual values showed that the most limiting constraints were, in descending

302 order, bioavailable zinc, EPA+DHA (eicosapentaenoic acid + docosahexaenoic acid), energy intake,

303 sodium and saturated fatty acids in men and bioavailable zinc, EPA+DHA and sodium in women. The

304 redistribution between ruminant meat and pork across modeling scenarios was driven by the

305 compromise between satisfying the nutritional constraints for bioavailable zinc and iron and sodium

306 requirements and the environmental constraint of GHGe reduction, as tested by alternative models

307 where we allowed some flexibility in the requirements for each of these nutrients one by one (data not

308 shown).

309 The sensitivity analysis also showed that the nutritional constraints for bioavailable zinc and iron were

310 determinant for the distribution between meat and whole grains products having a phytate content that

311 limit the zinc and iron bioavailabilities. Indeed, as shown in Appendix F, we verified that allowing

312 some flexibility for bioavailable zinc led to meat reduction together with whole grains and starch

313 foods increase (in men: $110 \mathrm{~g} / \mathrm{d} v s .2 \mathrm{~g} / \mathrm{d}$ of whole grains and starch foods with $v s$. without flexibility,

314 respectively, under the 50\% reduction in GHGe scenario).

315 Moreover, as shown in Appendix G, the constraint on livestock co-products had little influence on the

316 modeling results that were fairly similar with or without considering this constraint.

\section{4. Discussion}

318 In the present diet optimization study, the minimal changes in current French diets necessary to first

319 meet nutrient reference values and then reduce GHGe by up to $50 \%$ were characterized by an overall

320 decrease in the consumption of foods of animal origin with notably suppression of milk and strong

321 reductions in dairy products and cheese, together with a stable but largely redistributed meat

322 consumption in favor of poultry and pork and against ruminant meat, as well as marked increases in

323 the consumptions of legumes. It should be noted that strong dietary changes were induced as soon as

324 the first, basal stage consisting in modelling diets meeting nutrient reference values (under 
acceptability and moderation constraints), without any reduction in GHGe (which were however constrained to avoid any increase). From this first stage, the consumption of animal products decreases and the model opted for organic plant products, which are more efficient than non-organic ones to limit GHGe. During the second stage, GHGe reductions by up to $50 \%$ mainly resulted from a redistribution between meat types against ruminant meat, within total consumptions of meat and animal products remaining relatively stable. Noteworthy, the model selects the most efficient farming practice for each food (organic or not) thus the entire optimized consumption of each food item is either organic or conventional which does not reflect the reality of consumer behavior.

Notably, in addition to food behaviors, a major challenge to improve the sustainability of food systems is the reduction of losses and waste (44). The lack of quantitative data about waste for each food did not allow us to consider this dimension in our models. This is all the more complex, as waste occurs at each link of the food system chain and depends on both the production and processing methods

This study, by considering environmental pressures associated with food production while accounting for farming practices, as well as numerous detailed food items, allowed intra-group substitutions by favoring less emitter foods. This brings new insights since nowadays most French consumers are unlikely to be ready to follow drastic plant-based diets such as vegetarian or vegan diets, that would represent a radical change in eating habits for the highest consumers of animal products, and would require steps over time. In the meantime, small, low-impact dietary changes for a large proportion of the population are probably more acceptable than substantial changes as strong changes may need more time (45). Overall, our results are coherent with literature findings comparing emissions from observed diets more or less rich in animal products, which have documented lower emissions for diets richer in plant foods $(7,46-48)$. However, such observed diets do not necessarily meet the nutritional requirements.

Optimization modelling enables to identify environmental-friendly diets in line with nutrient requirements, (e.g. by avoiding counter-productive effects such as increase in consumption of sweet and fat products) (15). Scientific literature using diet optimization for exploring potential GHGe reduction under nutrient constraints is plentiful $(7-10,48)$. Overall, from these studies, it appears that a drastic and specific reduction of ruminant meat as well as dairy products consumption is the main lever for GHGe reduction from diet, which is in line with our results. We indeed found that dairy products and ruminant meat have to be drastically decreased, without being totally suppressed, which is somewhat different from the results of a recent diet optimization study that identified the need to completely eliminate ruminant meat while maintaining dairy products (excluding butter and cheese) to comply with the 2030 and 2050 GHGe reduction targets (being much stronger than those modelled here) in the Netherlands (49). However this study, as well as most of the others, did not take into account nutrient bioavailability in nutrient constraints and did not include coproduction constraints, 
whereas these important parameters may shape the modelling results and the order of magnitude of potential decreases and increases according to food groups (9). Herein, as previously done (26-28), we have considered and controlled the bioavailability of iron and zinc using validated equations for their absorption. We have shown that considering the bioavailability of iron and zinc was crucial for the concomitant variations in meat and whole grains products, whereas considering beef-milk coproduction had little influence in our context.

A wide heterogeneity exists in terms of methodological aspects across modelling studies (50). First, the number of food items can vary greatly and we worked with a relatively large number of food items ( 250) (9), with the notable feature of allowing the choice (or a mix) between two modes of production (organic or conventional) for each food item. Second, contrary to what has been most often done, we have considered constraints on food groups but not on food items so as to allow intra-group substitutions. These acceptability constraints based on the $95^{\text {th }}$ percentile of each population, including participants with healthier diets than the general population, allowed stronger increases in some food groups. Finally, we have adopted a quadratic rather than a linear formulation for the objective function of diet departure to minimize, so as to favor more numerous but smaller changes rather than fewer but larger changes during optimization (51). All these methodological choices have provided levers for optimized diets, since we had a wide inventory of food items and since intra-group substitutions were favored by different means as modeled here.

In our particular context, under all the considered nutritional and acceptability constraints and by accounting for the influence of anti-nutritional factors like phytate on zinc and iron bioavailabilities, total meat was maintained relatively stable, because of a decrease in whole grains and starchy foods (and thus a decrease in phytate), although it was qualitatively remodeled in disfavor of ruminant meat so as to reduce GHGe. In line with our results, a diet optimization study among old Dutch adults with $50 \%$ reduction in GHGs found unchanged total meat consumption with an increased contribution of poultry and pork and a decreased contribution of beef (52).

Several options regarding plant foods merit further discussion. In the optimized diets, non-alcoholic beverages (including coffee and tea) were strongly reduced (up to -54\%), as they are poor in nutrients and represent important environmental pressures at the post-production stage. However, as culturally deeply entrenched in our usual diets, such drops could be an important limitation and all the more so since positive health effects have been reported (53). It should be noted that whole grains and starchy foods, whose beneficial role on health is well-documented (54), were lowered in optimized diets (almost in men), and this may be ascribed to their phytates content limiting the iron and zinc bioavailability. Such a prominent role in optimized solutions raises the issue related to nutritional constraints relying on nutritional references which are based on calculated physiological requirements 
as for zinc, for instance, reliable biomarkers are lacking (55). Thus, while we have defined the nutrient constraints according to the French nutritional references and the literature equations for bioavailability, the methods of definition may be highly conservative and slightly lower intakes may not result in clear adverse effect on health, such as over-deficiency. Of note, the nutritional reference for fiber (i.e. $>30 \mathrm{~g} / \mathrm{d}$ ) favors the increase in foods with high content such as legumes, while reducing the ruminant meat for reducing GHGe required a reduction in phytate intake to allow sufficient absorption of iron and zinc, which in turn has favored the reduction of starchy foods. This was clearly illustrated by an alternative model allowing flexibility on zinc, with which whole grains foods did increase. Moreover, in the optimized diets, fish consumption was limited by an upper value. Fish and seafood are the major supplier of EPA and DHA that should be consumed at the highest level of their reference value. This reflects the fact that EPA+DHA is a limiting constraint for more sustainable diets and suggest that other and presumably better sustainable diets might be identified when introducing other new sources of these fatty acids.

Finally, the proportion of organic foods drastically increased (in weight) from $\sim 30 \%$ in the observed diets to $\sim 70 \%$ in all the optimized diets, which explained the monetary cost increase of optimized diets (56). At the individual diet level, we previously reported that regular organic food consumers exhibit diets with a lower impact regarding GHGe, land use and energy demand but dietary patterns (i.e. plant-based patterns) prevailed on the mode of production in this association (22). However, at the food item level, organic farming may play a substantial role in reducing GHGe, depending on the food considered $(23,57,58)$. Our results illustrate that when optimizing diets by selecting specific products like in the present study, rather than by only substituting some conventional by organic products at constant diet, as some consumers can do, organic foods can greatly help to the reduction of GHGe, as previously shown in our observational studies (59). The consumption of organic foods increases from the first step (i.e. $0 \%$ reduction in GHGe corresponding to modeling diet with $\mathrm{GHGe} \leq$ observed value) which means that the foods preferentially selected to respect the nutritional constraints are more efficient as organic to maintain GHGe. However, due to modeling, one food is selected $100 \%$ as organic or $100 \%$ as conventional what does not reflect the reality of behaviors. This is interesting as an increased consumption of organic foods can have beneficial consequences on two levels. First, on the environmental level as organic production systems also exhibit improved energy efficiency (60), better biophysics and biological quality of soils $(57,61)$ and are valuable for plant and animal biodiversity $(57,60,61)$. Second, on the sanitary level, as high plant-based diets based on organic agriculture may lead to much lower exposure to pesticide residues $(22,62,63)$, motivating the promotion of plant products produced without synthetic pesticides in the new French food-based dietary guidelines (64).

\footnotetext{
As regards the obtained solutions, optimized diets exhibited high consumption of fruits and vegetables
} $(>500 \mathrm{~g} / \mathrm{d})$, low consumption of red meat $(<500 \mathrm{~g} /$ week $)$, processed meat $(<150 \mathrm{~g} /$ week $)$, sweet 
products, low intake in salt and moderated consumption of dairy products, in line with the French food-based guidelines (42). Importantly, consumption of legumes among menopausal women was somewhat low and the consumption of whole grains and starchy foods was very low in men. As scientific literature has documented a notable beneficial role of plant-food diets, beyond fiber intake which are controlled in the present study, for health and environment (3), further steps of the transition, probably further away from the observed diets would require to introduce a higher plant versus animal food ratio. For instance, in the same cohort we previously described low emitting dietary patterns (GHGe for production lower than about $2.2 \mathrm{~kg} \mathrm{CO}_{2} \mathrm{eq}$ ) that were richer in plant-based food than the present solution but nutritional adequacy was not assessed (24). Higher shares of healthy plant protein such as whole grains and lower consumption of animal protein as red meat are considered as part of a healthy diet as documented by epidemiological data $(65,66)$ and may be warranted for a full sustainable transition together with GHGe. Finally, the nutritional values of highly plant-based diets should be tested in the future by deleting or relaxing acceptability constraints, considering alignment with healthy eating patterns as defined from epidemiological data or by using hierarchical optimization as we did in a recent study (67). Finally, it has been previously documented that healthier diets are often more expensive (68). In line with this, the optimized diets were more expensive than the observed diet, constituting a potential barrier for some consumers. Without appropriate policies, this may jeopardize food security due to inaccessibility and potential low availability for vulnerable populations.

Some limitations of our work should be highlighted. First, the NutriNet-Santé cohort included volunteers who were probably more concerned by health and diet issues than the general population, limiting extrapolation to the general population as these participants exhibit diet rich in plant-based food. For instance, lowering energy intake is a well-known lever for reducing GHGe $(69,70)$ but in this population including "small eaters", energy intake increased in the basal model to reach the requirement. Second, post-farm environmental pressures for organic agriculture are lacking, thus life cycle assessments were limited to farm activities which have most impacts in the food system. Therefore, our scenarios may be insufficient to meet the global climatic objective, since some steps following food production were not considered. Concerning environmental indicators, LCA were used while it is recognized that some ecosystem services related to agroecological practices are misestimate by this method (25). Third, beyond GHGe, we considered two other environmental pressures for descriptive purpose, those three allowing an acceptable representativeness of the overall environmental impact (43), but other dimensions such as water use or biodiversity should be studied. However, in further works, it would be very important to consider water use in particular in the context of vegetable and fruit and the production of corn, mainly for feeding monogastric livestock breeding. We observed a decrease in land occupation with the gradual reduction in GHGe. Reallocation of released land may induce important fluctuations in GHGe which are the results of carbon balance of managed forests, agricultural soil organic carbon stocks soil and reallocation 
(grassland, deforestation, afforestation, artificialization etc.)(71). But, an important factor that was not considered is land use reallocation since this analysis used attributional LCAs. Thus, the change in the type of meat consumed would have also an effect on the demand for arable land and therefore on carbon stocks and on GHGs (72). Notably, in addition to food behaviors, a major challenge to improve the sustainability of food systems is the food losses and waste reduction (44). The lack of quantitative data about waste for each food did not allow us to consider this important dimension in our models. This is all the more complex, as waste occurs at each link of the food system chain and depends on both the type production and level of processing. The reallocation of permanent grasslands is also an issue We have also assumed, as in most diet optimization studies (9), that the most acceptable diets are those the closest to the observed diets. While this classical assumption makes it possible to define a simple and very restrictive metric of cultural acceptability, it is known to account only very imperfectly for true acceptability as stronger dietary changes may occur, at least in certain segments of the population. Besides, this study integrates many strengths such as the level of detail for food consumption, the detailed and reliable consideration of the updated nutritional recommendations (including bioavailability of the micronutrients of concern in our context, iron and zinc, which is seldom done), the consideration of different food production methods and the corresponding environmental indicators.

In conclusion, this study in adults provides detailed results on the possible dietary changes that can be implemented to mitigate GHGe up to 50\% with minimal departure from the observed diet. We were here able to identify more sustainable diets, being nutritionally adequate and culturally acceptable, and from which meat was not excluded. Because the present optimized nutrition model preferentially allowed intra-category substitutions, the plant/animal food ratio was not noticeably altered. Although adequate according to a large set of lower and upper nutrient reference values, the modelled diets may be sub-optimal for long-term health, which may benefit from further decrease in red meat and higher increases in whole grains. Furthermore, reducing the consumption of foods of animal origin, particularly beef and lamb, as well as milk and dairies, is necessary not only for environmental or health reasons but also for animal welfare considerations. Lastly, future research will be needed to document even greater reductions as this $50 \%$ is unlikely to be sufficient and further research focusing on specific subgroups, e.g. according to age or socioeconomic status would be of interest to fine-tune the optimized diet.

\section{Acknowledgements}

We thank Cédric Agaesse (dietitian); Thi Hong Van Duong, Younes Esseddik (IT manager), Régis Gatibelza, Djamal Lamri, Jagatjit Mohinder and Aladi Timera (computer scientists); Julien Allegre, Nathalie Arnault, Laurent Bourhis and Fabien Szabo de Edelenyi, PhD (supervisor) (datamanager/statisticians) for their technical contribution to the NutriNet-Santé study and Nathalie 
510 Druesne-Pecollo, $\mathrm{PhD}$ (operational coordination). We thank all the volunteers of the NutriNet-Santé

511 cohort.

512 5. The authors' contributions are as follows:

513 EKG, BA, MT, and SH conducted the study.

514 EKG, JB, BL, SH, DL and PP conducted the research and implemented databases.

515 EKG, HF, AD, and FM conducted the diet optimization.

516 EKG performed statistical analyses and drafted the manuscript.

517 All authors critically helped in the interpretation of results, revised the manuscript and provided relevant

518 intellectual input. They all read and approved the final manuscript.

519 EKG had primary responsibility for the final content, she is the guarantor.

\section{6. Conflict of Interest}

521 No author declared conflict of interest.

\section{7. Funding}

523 The NutriNet-Santé study is funded by French Ministry of Health and Social Affairs, Santé Publique

524 France, Institut National de la Santé et de la Recherche Médicale, Institut National de la Recherche

525 Agronomique, Conservatoire National des Arts et Métiers, and Sorbonne Paris Nord University. The

526 BioNutriNet project was supported by the French National Research Agency (Agence Nationale de la

527 Recherche) in the context of the 2013 Programme de Recherche Systèmes Alimentaires Durables

528 (ANR-13-ALID-0001). The funders had no role in the study design, data collection, analysis,

529 interpretation of data, preparation of the manuscript, and decision to submit the paper. 


\section{References}

1. The intergovernmental panel on climate change (IPCC). Global Warming of $1.5^{\circ} \mathrm{C}$ [Internet]. [cited $2019 \mathrm{Jul}$ 18]. Available from: https://www.ipcc.ch/sr15/

2. Food production is responsible for one-quarter of the world's greenhouse gas emissions [Internet]. Our World in Data. [cited 2020 Jun 5]. Available from: https://ourworldindata.org/food-ghg-emissions

3. Willett W, Rockström J, Loken B, Springmann M, Lang T, Vermeulen S, et al. Food in the Anthropocene: the EAT-Lancet Commission on healthy diets from sustainable food systems. Lancet. 2019 Jan 16;393(10170):447-92.

4. Tilman D, Clark M. Global diets link environmental sustainability and human health. Nature. 2014 Nov 27;515(1476-4687 (Electronic)):518-22.

5. Couturier C, Charru M, Doublet S, Pointereau P. The Afterres 2050 le scénario [Internet]. 2016 [cited 2020 Jun 8]. Available from: https://afterres2050.solagro.org/wpcontent/uploads/2020/02/Afterres2050-eng.pdf

6. Springmann M, Wiebe K, Mason-D'Croz D, Sulser TB, Rayner M, Scarborough P. Health and nutritional aspects of sustainable diet strategies and their association with environmental impacts: a global modelling analysis with country-level detail. Lancet Planet Health. 2018;2(10):e451-61.

7. Aleksandrowicz L, Green R, Joy EJM, Smith P, Haines A. The Impacts of Dietary Change on Greenhouse Gas Emissions, Land Use, Water Use, and Health: A Systematic Review. Wiley AS, editor. PLOS ONE. 2016 Nov 3;11(11):e0165797.

8. Perignon M, Vieux F, Soler L-G, Masset G, Darmon N. Improving diet sustainability through evolution of food choices: review of epidemiological studies on the environmental impact of diets. Nutrition Reviews. 2017 Jan;75(1):2-17.

9. van Dooren C. A Review of the Use of Linear Programming to Optimize Diets, Nutritiously, Economically and Environmentally. Front Nutr. 2018;5:48.

10. Wilson N, Cleghorn CL, Cobiac LJ, Mizdrak A, Nghiem N. Achieving Healthy and Sustainable Diets: A Review of the Results of Recent Mathematical Optimization Studies. Adv Nutr. 2019 01;10(Suppl_4):S389-403.

11. Lindgren E, Harris F, Dangour AD, Gasparatos A, Hiramatsu M, Javadi F, et al. Sustainable food systems-a health perspective. Sustain Sci. 2018;13(6):1505-17.

12. Springmann M, Godfray HCJ, Rayner M, Scarborough P. Analysis and valuation of the health and climate change cobenefits of dietary change. PNAS. 2016 Apr 12;113(15):4146-51.

13. Hemler EC, Hu FB. Plant-Based Diets for Personal, Population, and Planetary Health. Adv Nutr. 2019 Nov 1;10(Supplement_4):S275-83.

14. Clark MA, Springmann M, Hill J, Tilman D. Multiple health and environmental impacts of foods. PNAS. 2019 Nov 12;116(46):23357-62.

15. Stoll-Kleemann S, Schmidt UJ. Reducing meat consumption in developed and transition countries to counter climate change and biodiversity loss: a review of influence factors. Reg Environ Change. 2017 Jun;17(5):1261-77. 
16. Hartmann C, Siegrist M. Consumer perception and behaviour regarding sustainable protein consumption: A systematic review. Trends in Food Science \& Technology. 2017 Mar 1;61:1125.

17. Manners R, Blanco-Gutiérrez I, Varela-Ortega C, Tarquis AM. Transitioning European ProteinRich Food Consumption and Production towards More Sustainable Patterns - Strategies and Policy Suggestions. Sustainability. 2020 Jan;12(5):1962.

18. Graça J, Godinho CA, Truninger M. Reducing meat consumption and following plant-based diets: Current evidence and future directions to inform integrated transitions. Trends in Food Science \& Technology. 2019 Sep 1;91:380-90.

19. de Gavelle E, Davidenko O, Fouillet H, Delarue J, Darcel N, Huneau J-F, et al. Self-declared attitudes and beliefs regarding protein sources are a good prediction of the degree of transition to a low-meat diet in France. Appetite. 2019 Nov 1;142:104345.

20. Perignon M, Masset G, Ferrari G, Barré T, Vieux F, Maillot M, et al. How low can dietary greenhouse gas emissions be reduced without impairing nutritional adequacy, affordability and acceptability of the diet? A modelling study to guide sustainable food choices. Public Health Nutrition. 2016 Oct;19(14):2662-74.

21. Kurian M. The water-energy-food nexus: Trade-offs, thresholds and transdisciplinary approaches to sustainable development. Environmental Science \& Policy. 2017 Feb 1;68:97106.

22. Baudry J, Pointereau P, Seconda L, Vidal R, Taupier-Letage B, Langevin B, et al. Improvement of diet sustainability with increased level of organic food in the diet: findings from the BioNutriNet cohort. Am J Clin Nutr. 2019 Apr 1;109(4):1173-88.

23. Clark M, Tilman D. Comparative analysis of environmental impacts of agricultural production systems, agricultural input efficiency, and food choice. Environmental Research Letters. 2017 Jun 1;12(6):064016.

24. Seconda L, Baudry J, Alles B, Boizot-Szantai C, Soler L-G, Galan P, et al. Comparing nutritional, economic, and environmental performances of diets according to their levels of greenhouse gas emissions. Clim Change. 2018 May;148(1-2):155-72.

25. van der Werf HMG, Knudsen MT, Cederberg C. Towards better representation of organic agriculture in life cycle assessment. Nature Sustainability. 2020 Jun;3(6):419-25.

26. Barré T, Perignon M, Gazan R, Vieux F, Micard V, Amiot M-J, et al. Integrating nutrient bioavailability and co-production links when identifying sustainable diets: How low should we reduce meat consumption? PLoS ONE. 2018;13(2):e0191767.

27. Ferguson EL, Darmon N, Briend A, Premachandra IM. Food-based dietary guidelines can be developed and tested using linear programming analysis. J Nutr. 2004 Apr;134(4):951-7.

28. Deptford A, Allieri T, Childs R, Damu C, Ferguson E, Hilton J, et al. Cost of the Diet: a method and software to calculate the lowest cost of meeting recommended intakes of energy and nutrients from local foods. BMC Nutrition. 2017 Mar 14;3(1):26.

29. European Commission. Paris Agreement [Internet]. Climate Action - European Commission. 2016 [cited $2021 \mathrm{Feb} 5$ ]. Available from: https://ec.europa.eu/clima/policies/international/negotiations/paris_en 
30. Hercberg S, Castetbon K, Czernichow S, Malon A, Mejean C, Kesse E, et al. The Nutrinet-Sante Study: a web-based prospective study on the relationship between nutrition and health and determinants of dietary patterns and nutritional status. BMC Public Health. 2010;10(14712458):242.

31. Vergnaud A-C, Touvier M, Méjean C, Kesse-Guyot E, Pollet C, Malon A, et al. Agreement between web-based and paper versions of a socio-demographic questionnaire in the NutriNetSanté study. Int J Public Health. 2011 Aug 1;56(4):407-17.

32. Touvier M, Mejean C, Kesse-Guyot E, Pollet C, Malon A, Castetbon K, et al. Comparison between web-based and paper versions of a self-administered anthropometric questionnaire. EurJEpidemiol. 2010 May;25:287-96.

33. Hagströmer M, Oja P, Sjöström M. The International Physical Activity Questionnaire (IPAQ): a study of concurrent and construct validity. Public Health Nutrition [Internet]. 2006 Sep [cited 2016 Apr 28];9(06). Available from: http://www.journals.cambridge.org/abstract_S1368980006001261

34. Baudry J, Méjean C, Allès B, Péneau S, Touvier M, Hercberg S, et al. Contribution of Organic Food to the Diet in a Large Sample of French Adults (the NutriNet-Santé Cohort Study). Nutrients. 2015;7(10):8615-32.

35. Council Regulation (EC) No 834/2007 of 28 June 2007 on organic production and labelling of organic products and repealing Regulation (EEC) No 2092/91 [Internet]. Available from: https://eur-lex.europa.eu/eli/reg/2007/834/oj

36. Etude Nutrinet-Santé. Table de composition des aliments de l'étude Nutrinet-Santé (NutrinetSanté Study Food Composition Database). Paris: Economica. 2013;

37. Pointereau P, Langevin B, Gimaret M. DIALECTE, a comprehensive and quick tool to assess the agro-environmental performance of farms. In 2012. Available from:

http://ifsa.boku.ac.at/cms/index.php?id=ifsa2012

38. Idèle. Chiffres clés Bovins 2016. 2016.

39. France Agrimer. Filière bovine, quotas laitiers. 2012 [cited 2020 Sep 22];12. Available from: https://www.franceagrimer.fr/fam/content/download/14506/document/filière bovine, quotas laitiers février $2012 \mathrm{~A} 4 . \mathrm{pdf}$

40. French Agency for Food, Environmental and Occupational Health Safety (Anses). Actualisation des repères du PNNS : élaboration des références nutritionnelles [Internet]. Maison Alfort: ANSES; 2016 Dec. Available from: Available from: https://www.anses.fr/fr/system/files/NUT2012SA0103Ra-2.pdf

41. Dietary Reference Values |DRV Finder [Internet]. EFSA. [cited 2021 Jan 22]. Available from: https://www.efsa.europa.eu/en/interactive-pages/drvs

42. HCSP. Statement related to the revision of the 2017-2021 French Nutrition and Health Programme's dietary guidelines for adults [Internet]. Paris: Haut Conseil de la Santé Publique; 2017 Feb [cited 2019 Feb 5]. Available from: https://www.hcsp.fr/explore.cgi/avisrapportsdomaine?clefr=653

43. Kramer GF, Tyszler M, Veer PV, Blonk H. Decreasing the overall environmental impact of the Dutch diet: how to find healthy and sustainable diets with limited changes. Public Health Nutr. 2017 Jun;20(9):1699-709. 
44. HLPE. Food losses and waste in the context of sustainable food systems. A report by the High Level Panel of Experts on Food Security and Nutrition of the Committee on World Food Security. Rome, Italy; 2014 p. 117.

45. Mariotti F, editor. Vegetarian and Plant-Based Diets in Health and Disease Prevention [Internet]. Elsevier; 2017 [cited 2021 Feb 14]. Available from: https://linkinghub.elsevier.com/retrieve/pii/C20150003999

46. Chai BC, van der Voort JR, Grofelnik K, Eliasdottir HG, Klöss I, Perez-Cueto FJA. Which Diet Has the Least Environmental Impact on Our Planet? A Systematic Review of Vegan, Vegetarian and Omnivorous Diets. Sustainability. 2019 Jan;11(15):4110.

47. Macdiarmid JI, Whybrow S. Nutrition from a climate change perspective. Proceedings of the Nutrition Society. undefined/ed;1-8.

48. Auestad N, Fulgoni VL III. What current literature tells us about sustainable diets: emerging research linking dietary patterns, environmental sustainability, and economics. AdvNutr. 2015 Jan;6(2156-5376 (Electronic)):19-36.

49. Broekema R, Tyszler M, van 't Veer P, Kok FJ, Martin A, Lluch A, et al. Future-proof and sustainable healthy diets based on current eating patterns in the Netherlands. Am J Clin Nutr. 2020 Nov 11;112(5):1338-47.

50. Gazan R, Brouzes CMC, Vieux F, Maillot M, Lluch A, Darmon N. Mathematical Optimization to Explore Tomorrow's Sustainable Diets: A Narrative Review. Adv Nutr. 2018 Sep 1;9(5):60216.

51. Persson M, Fagt S, Pires SM, Poulsen M, Vieux F, Nauta MJ. Use of Mathematical Optimization Models to Derive Healthy and Safe Fish Intake. The Journal of Nutrition. 2018 Feb $1 ; 148(2): 275-84$.

52. Grasso AC, Olthof MR, van Dooren C, Broekema R, Visser M, Brouwer IA. Protein for a Healthy Future: How to Increase Protein Intake in an Environmentally Sustainable Way in Older Adults in the Netherlands. The Journal of Nutrition. 2021 Jan 4;151(1):109-19.

53. Poole R, Kenned O, Roderick P, Fallowfield J, Haye P, Parkes J. Coffee consumption and health: umbrella review of meta-analyses of multiple health outcomes. BMJ [Internet]. 2018 Jan 12 [cited 2020 Dec 8];360. Available from: https://www.ncbi.nlm.nih.gov/pmc/articles/PMC5765813/

54. McRae MP. Health Benefits of Dietary Whole Grains: An Umbrella Review of Meta-analyses. J Chiropr Med. 2017 Mar;16(1):10-8.

55. Bornhorst J, Kipp AP, Haase H, Meyer S, Schwerdtle T. The crux of inept biomarkers for risks and benefits of trace elements. TrAC Trends in Analytical Chemistry. 2018 Jul 1;104:183-90.

56. Boizot-Szantai C, Hamza O, Soler L-G. Organic consumption and diet choice: An analysis based on food purchase data in France. Appetite. 2017 01;117:17-28.

57. Tuomisto HL, Hodge ID, Riordan P, Macdonald DW. Does organic farming reduce environmental impacts? - A meta-analysis of European research. Journal of Environmental Management. 2012 Dec;112:309-20.

58. Meier MS, Stoessel F, Jungbluth N, Juraske R, Schader C, Stolze M. Environmental impacts of organic and conventional agricultural products--are the differences captured by life cycle assessment? J Environ Manage. 2015 Feb 1;149:193-208. 
59. Lacour C, Seconda L, Allès B, Hercberg S, Langevin B, Pointereau P, et al. Environmental Impacts of Plant-Based Diets: How Does Organic Food Consumption Contribute to Environmental Sustainability? Front Nutr. 2018;5:8.

60. Reganold JP, Wachter JM. Organic agriculture in the twenty-first century. Nature Plants. 2016 Feb 3;2(2):15221.

61. Gomiero T, Pimentel D, Paoletti MG. Environmental Impact of Different Agricultural Management Practices: Conventional vs. Organic Agriculture. Critical Reviews in Plant Sciences. 2011 Jan;30(1-2):95-124.

62. Fleury S, Rivière G, Allès B, Kesse-Guyot E, Méjean C, Hercberg S, et al. Exposure to contaminants and nutritional intakes in a French vegetarian population. Food Chem Toxicol. 2017 Jul 25;109(Pt 1):218-29.

63. Rebouillat P, Vidal R, Cravedi J-P, Taupier-Letage B, Debrauwer L, Gamet-Payrastre L, et al. Estimated dietary pesticide exposure from plant-based foods using NMF-derived profiles in a large sample of French adults. Eur J Nutr. 2020 Jul 30;

64. Santé publique France - Santé publique France présente les nouvelles recommandations sur l'alimentation, l'activité physique et la sédentarité [Internet]. [cited 2019 Mar 1]. Available from: https://www.santepubliquefrance.fr/Accueil-Presse/Tous-les-communiques/Santepublique-France-presente-les-nouvelles-recommandations-sur-l-alimentation-l-activite-physiqueet-la-sedentarite

65. Mariotti F. Animal and Plant Protein Sources and Cardiometabolic Health. Adv Nutr. 2019 01;10(Suppl_4):S351-66.

66. Naghshi S, Sadeghi O, Willett WC, Esmaillzadeh A. Dietary intake of total, animal, and plant proteins and risk of all cause, cardiovascular, and cancer mortality: systematic review and doseresponse meta-analysis of prospective cohort studies. BMJ. 2020 Jul 22;370:m2412.

67. Seconda L, Fouillet H, Huneau J-F, Pointereau P, Baudry J, Langevin B, et al. Conservative to disruptive diets for optimizing nutrition, environmental impacts and cost in French adults from the NutriNet-Santé cohort. Nature Food. 2021 Mar 11;1-9.

68. Darmon N, Drewnowski A. Contribution of food prices and diet cost to socioeconomic disparities in diet quality and health: a systematic review and analysis. Nutr Rev. 2015 Oct;73(10):643-60.

69. Nelson ME, Hamm MW, Hu FB, Abrams SA, Griffin TS. Alignment of Healthy Dietary Patterns and Environmental Sustainability: A Systematic Review12. Adv Nutr. 2016 Nov 10;7(6):1005-25.

70. Vieux F, Darmon N, Touazi D, Soler L, Soler LG. Greenhouse gas emissions of self-selected individual diets in France: Changing the diet structure or consuming less? EcolEcon. 2012;75:91-101.

71. Smith P, House JI, Bustamante M, Sobocká J, Harper R, Pan G, et al. Global change pressures on soils from land use and management. Global Change Biology. 2016;22(3):1008-28.

72. Garnett T. Livestock-related greenhouse gas emissions: impacts and options for policy makers. Environmental Science \& Policy. 2009 Jun 1;12(4):491-503. 
736 Figure 1: Overall composition (g/d) of the observed and optimized diets according to the modelling scenario and population group (color figure)

Main food groups intakes $(\mathrm{g} / \mathrm{d})$ in the observed diets and in the diets being nutritionally, culturally and environmentally optimized so as to ensure gradual reduction in greenhouse gas emissions (GHGe) from 0 to 50\%. Abbreviations: Obs, observed diet. A: men, B: premenopausal women, C: menopausal

741 women.

742 Figure 2: Composition in animal-based foods in the observed and optimized diets 743 according to the modelling scenario and population group (color figure)

744 Detailed animal foods intakes (g/d) in the observed diets and in the diets being nutritionally, culturally 745 and environmentally optimized so as to ensure gradual reduction in greenhouse gas emissions (GHGe) 746 from 0 to 50\%. Abbreviations: Obs, observed diet. A: men, B: premenopausal women, C: menopausal 747 women.

Figure 3: Composition in plant-based foods in the observed and optimized diets according to the modelling scenario and population group (color figure)

Detailed plant-based foods intakes $(\mathrm{g} / \mathrm{d})$ in the observed diets and in the diets being nutritionally, culturally and environmentally optimized so as to ensure gradual reduction in greenhouse gas emissions (GHGe) from 0 to 50\%. Abbreviations: Obs, observed diet. A: men, B: premenopausal women, $\mathrm{C}$ : menopausal women. 